\title{
Characterization of Osteocalcin (BGP) and Matrix Gla Protein (MGP) Fish Specific Antibodies: Validation for Immunodetection Studies in Lower Vertebrates
}

\author{
D. C. Simes, ${ }^{1}$ M. K. Williamson, ${ }^{2}$ B. J. Schaff, ${ }^{1}$ P. J. Gavaia, ${ }^{1}$ P. M. Ingleton, ${ }^{3}$ P. A. Price, ${ }^{2}$ M. L. Cancela ${ }^{1}$ \\ ${ }^{1}$ CCMAR-University of Algarve, Faro 8005-139, Portugal \\ ${ }^{2}$ Division of Biology, University of California San Diego, La Jolla, CA 92093-0368, USA \\ ${ }^{3}$ Division of Musculo-Skeletal Medicine, Institute of Endocrinology, University of Sheffield, Beech Hill Rd, Sheffield S10 2RX, UK
}

Received: 4 April 2003 / Accepted: 2 June 2003 / Online publication: 15 December 2003

\begin{abstract}
In fish species the basic mechanisms of bone development and bone remodeling are not fully understood. The classification of bone tissue in teleosts as cellular or acellular and the presence of transitional states between bone and cartilage and the finding of different types of cartilage in teleosts not previously recognized in higher vertebrates emphasizes the need for a study on the accumulation of the Gla-containing proteins MGP and BGP at the cellular level. In the present study, polyclonal antibodies developed against BGP and MGP from $A$. regius (a local marine teleost fish) and against MGP from G. galeus (a Pacific Ocean shark), were tested by Western blot for their specificity against BGP and MGP from several other species of teleost fish and shark. For this purpose we extracted and purified both proteins from various marine and freshwater teleosts, identified them by N-terminal amino acid sequence analysis and confirmed the presence of gamma-carboxylation in the proteins with the use of a stain specific for Gla residues. Each antibody recognized either BGP or MGP with no cross-reaction between proteins detected. All purified fish BGPs and MGPs tested were shown to be specifically recognized, thus validating the use of these antibodies for further studies.
\end{abstract}

Matrix Gla Protein (MGP) and Bone Gla Protein (BGP, osteocalcin) belong to the family of vitamin K-dependent (VKD), $\gamma$-carboxyglutamic acid (Gla)-containing proteins that have been unequivocally associated with bone formation and mineralization [1-4], and more recently, with vascular calcification [5-10].

MGP is a $10-15 \mathrm{kDa}$-secreted protein, containing 4-5 residues (depending on the species) of the $\mathrm{Ca}^{2+}$ binding Gla residue [11-15] while BGP is a small secreted protein with approximately $6 \mathrm{kDa}$ molecular weight and includes three Gla residues. Although there is little information about the regulation of expression of these proteins in teleosts, BGP in teleost fish has been shown to be associated with bone-like mineralized tissues pre-

Correspondence to: M. L. Cancela; E-mail: lcancela@ualg.pt sent in branchial arches, jaw, vertebra and scales $[15,16]$ while MGP was only recently found to accumulate, mainly in the extracellular matrix of calcified cartilage [15]. In this previous work, the MGP gene was found to be predominantly expressed in chondrocytes from branchial arches, with no expression detected in the different bone-like mineralized tissues analyzed while BGP mRNA was mainly located in bony tissues associated with osteoblast-like cells, as expected [15]. As previously seen in mammals and Xenopus, MGP mRNA was also found to be present in teleost soft tissues, predominantly in heart and kidney [15], with the expression of MGP in heart tissue mainly associated with two specific cell types, smooth muscle and endothelial cells [15].

We have recently developed specific polyclonal antibodies against BGP and MGP from the teleost fish $A$. regius [15] as well as against MGP purified from soupfin shark (Galeorhinus galeus) (our unpublished results). The purpose of the present work was to demonstrate the usefulness of these antibodies for studies of BGP/MGP accumulation and tissue distribution in marine and fresh water fish and amphibians. To achieve this goal we purified and characterized MGP and BGP from various fish species and from Xenopus and compared the ability of our antibodies to recognize these specific antigens.

\section{Material and Methods}

Extraction of MGP and BGP from Fish and Amphibian Tissues

Vertebra from Sparus aurata, Solea senegalensis and Prionace glauca, branchial arches from Halobatrachus didactylus and the entire skeleton of Xenopus laevis and Danio rerio were cleaned from adhering soft tissues and the Gla-containing proteins were extracted based on previously described procedures $[14,15,17]$. Briefly, the mineralized material was ground in a mortar with liquid nitrogen to less than $1 \mathrm{~mm}$ in diameter, 
extensively washed with $6 \mathrm{M}$ guanidine $\mathrm{HCl}$ and water and dried with acetone. The resulting powder was demineralized with $10 \%$ formic acid, dialyzed (SpectraPor 3) against $50 \mathrm{mM}$ $\mathrm{HCl}$, freeze-dried, re-suspended in $6 \mathrm{M}$ guanidine- $\mathrm{HCl}, 0.1 \mathrm{M}$ Tris-HCl pH 9, 10 mM EDTA, further dialyzed (SpectraPor 3; Spectrum, Gardena, CA, USA) against $5 \mathrm{mM}$ ammonium bicarbonate and freeze-dried [15]. P. glauca dialyzed extract showed a precipitate that was separated, dissolved in $50 \mathrm{mM}$ $\mathrm{HCl}$ and stored at $-80^{\circ} \mathrm{C}$. Samples were then analyzed by SDS-PAGE as described in "Electrophoresis and Blotting."

For all the other preparations, the crude extracts were ultrafiltrated using a Centricon-10 with $10 \mathrm{kDa}$ molecular weight cut-off (Amicon, Millipore, Bedford, MA, USA). The combined final filtrates containing BGP (lower than $10 \mathrm{kDa}$ ) were further desalted and concentrated using a Centricon-3 (3 kDa cut-off) (Amicon).

Both the filtrate and filter-retained samples were collected and their protein content was determined as described in "Protein Quantification." Proteins in each fraction were further analyzed by SDS-PAGE.

\section{Protein Quantification}

Total protein concentration in crude acid extracts was determined using the Commassie plus protein assay reagent (Pierce, Rockford, IL, USA) according to the manufacturer's protocol. For the determination of protein concentration of purified BGP samples, the value of $\mathrm{E}^{0.1 \%} 1 \mathrm{~cm}=1.33$ at $280 \mathrm{~nm}$ [18] was used. For MGP concentration determination the value of $\mathrm{E}^{0.1 \% 1 \mathrm{~cm}}=1.0$ at $280 \mathrm{~nm}$ was used (P.A. Price, personal communication).

\section{$N$-Terminal Protein Sequence Analysis}

$\operatorname{DrBGP}(D$. rerio $\mathrm{BGP})$ and $H d \mathrm{BGP}(H$. didactylus $\mathrm{BGP})$ purified proteins were directly deposed on a polybrene-coated glass fiber filter. PgMGP $(10 \mu \mathrm{g})(P$. glauca MGP) containing samples were loaded onto 4 lanes and fractionated on a $18 \%$ SDS-polyacrylamide gel, then transferred onto a PVDF membrane filter (Applied Biosystems, Foster City, CA, USA) and stained with Commassie Brilliant Blue in order to visualize protein bands. The band corresponding to PgMGP (around 18 $\mathrm{kDa}$ ) detected in each lane was cut for further identification by protein sequence analysis. Automatic Edman degradations were performed as described [13] using an Applied Biosystems Model 494 sequenator equipped with an on-line HPLC and employing the standard program supplied by the manufacturer. Phenylthiohidantoin (PTH) amino acid derivatives were separated by a $2.1 \mathrm{~mm} \times 22 \mathrm{~cm} \mathrm{C}-18$ reverse-phase HPLC column (Applied Biosystems) and the gradient conditions were those recommended by Applied Biosystems.

\section{Electrophoresis and Blotting}

Total protein $(20-30 \mu \mathrm{g})$ was dissolved in SDS sample buffer containing reducing agent (NuPage, Invitrogen, La Jolla, CA, USA), applied to a $12 \%$ or $4-12 \%$ gradient polyacrylamide precast gel containing $0.1 \%$ SDS (NuPage, Invitrogen) and fractionated at a constant 140 volts. The gels were stained either with $0.2 \%$ Commassie Brilliant Blue R-250 (C.I. 42660, Bio-Rad, Richmond, CA, USA), 10\% trichloroacetic acid, $10 \%$-sulfosalicylic acid or with a DBS-staining solution specific for Gla-containing proteins $[(8.5 \mathrm{mM}$ 4-diazobenzene sulfonic acid (DBS); Sigma, Spain; 6.4 mM NaNO 2 in $2 \mathrm{M}$ acetate buffer, $\mathrm{pH}$ 4.6)] as described in [19]. Lysozyme (Sigma) and protease factor Xa (New England Biolabs) were used, respectively, as negative and positive controls for the DBSstaining method. Blotting onto nitrocellulose (Invitrogen) was performed for $1 \mathrm{~h}$ at constant $80 \mathrm{~mA}$ using a Bio-Rad Mini Trans-Blot Cell system (Bio-Rad) and a Bis-Tris transfer buffer (NuPage, Invitrogen). The membranes were blocked for
$2 \mathrm{~h}$ with $5 \%(\mathrm{w} / \mathrm{v})$ non-fat dried milk powder in TBST (15 mM $\mathrm{NaCl}, 10 \mathrm{mM}$ Tris- $\mathrm{HCl}$ buffer, $\mathrm{pH} 8,0.05 \%$ Tween 20; Blotto) and then incubated overnight with $0.04 \mu \mathrm{g} / \mathrm{ml}$ anti- $A r$ MGP or anti- $A r$ BGP affinity-purified antiserum in Blotto or with anti$G g$ MGP polyclonal antibody diluted 1:100 in the same solution. Immunoreactive protein bands were detected using alkaline phosphatase-labeled goat anti-rabbit IgG antibody (Gibco-BRL, Paisley, UK) diluted 1:20,000 in TBST and visualized using NBT/BCIP substrate solution (Sigma) as described [20]. Negative controls consisted in the substitution of the primary antibody with phosphate-buffered saline $(150 \mathrm{mM}$ $\mathrm{NaCl}, 15 \mathrm{mM}$ sodium phosphate buffer, $\mathrm{pH} 7.2$; PBS) in the experiments with the purified antibody and with normal rabbit serum when using the non-purified antibody. Controls also included pre-incubation of the primary antibody for $1 \mathrm{~h}$ at room temperature with purified $A r \mathrm{MGP}$ and $A r \mathrm{BGP}$ purified protein (1:10 weight ratio).

\section{Dot-blot Analysis}

Purified protein samples were deposited in $1 \mu$ aliquots $(0.5 \mu \mathrm{g}$ total protein) onto a nitrocellulose membrane (Invitrogen). Membranes were allowed to dry for $1 \mathrm{~h}$ and blocked for $2 \mathrm{~h}$ with $5 \%(\mathrm{w} / \mathrm{v})$ dried milk powder in TBST. Incubation with anti- $A r$ MGP, anti- $A r$ BGP affinity-purified antibodies and anti-GgMGP polyclonal antiserum and detection of immunoreactive protein spots was performed as described in "Electrophoresis and blotting."

\section{ArBGP, ArMGP and GgMGP Antiserum}

MGP and BGP were purified from formic acid extracts of $A$. regius branchial arches as described [15]. Rabbit polyclonal antibodies against MGP and BGP from $A$. regius were obtained from Strategic BioSolutions (Ramona, CA, USA) using the purified protein adsorbed to polyvinylpyrrolidone (PVP40), as described [11, 15]. GgMGP (MGP from Galeorhinus galeus) antiserum was raised against purified GgMGP [21] using a described method [11].

Specificity of the antiserum was determined by Dot-blot and Western-blot immunoassays as described in "Electrophoresis and Blotting" using either the purified proteins ( $A r$ MGP and $A r \mathrm{BGP}$ ) [15] or the characterized MGP obtained from a crude extract of $P$. glauca calcified cartilage.

\section{Affinity Purification of ArBGP and ArMGP Antiserum}

Purified protein samples [15] (5 mg of $\operatorname{ArBGP}$ dissolved in 0.1 $\mathrm{M} \mathrm{NaHCO} 3,0.5 \mathrm{M} \mathrm{NaCl}$, pH 8.3 and $1.2 \mathrm{mg}$ of $A r \mathrm{MGP}$ resuspended in $0.2 \mathrm{M} \mathrm{NaHCO}_{3}, 4 \mathrm{M}$ urea) were coupled to the CNBr-activated Sepharose 4B resin (Amersham-Pharmacia, Piscataway, NJ) overnight at $4^{\circ} \mathrm{C}$. Adsorption of the $A r$ BGP and $A r$ MGP polyclonal antibodies was performed according to the manufacture's instructions. Bound antibodies were eluted with $100 \mathrm{mM}$ glycine pH 2.5 followed with $100 \mathrm{mM}$ triethylamine, $\mathrm{pH} 11.5$ and samples $(1 \mathrm{ml})$ were immediately neutralized by adding $100 \mu \mathrm{l}$ of $1 \mathrm{M}$ Tris- $\mathrm{HCl}, \mathrm{pH}$ 7. Absorption of the effluent at $280 \mathrm{~nm}$ was monitored. The resulting peak fractions were dialyzed against phosphate-buffer saline and stored at $-20^{\circ} \mathrm{C}$.

\section{Determination of BGP Theoretic Isoelectric Point}

Isoelectric point of BGPs from A. regius, S. aurata, D. rerio, $X$. laevis and B. taurus were calculated using the Peptide Statistics Tool (PEPSTATS) from biotools (http://biotools.umassmed.edu ). The complete mature sequence derived from cDNA was used in each case and values were calculated in the absence of either hydroxylation of proline or $\gamma$-carboxylation of glutamic acid residues. 


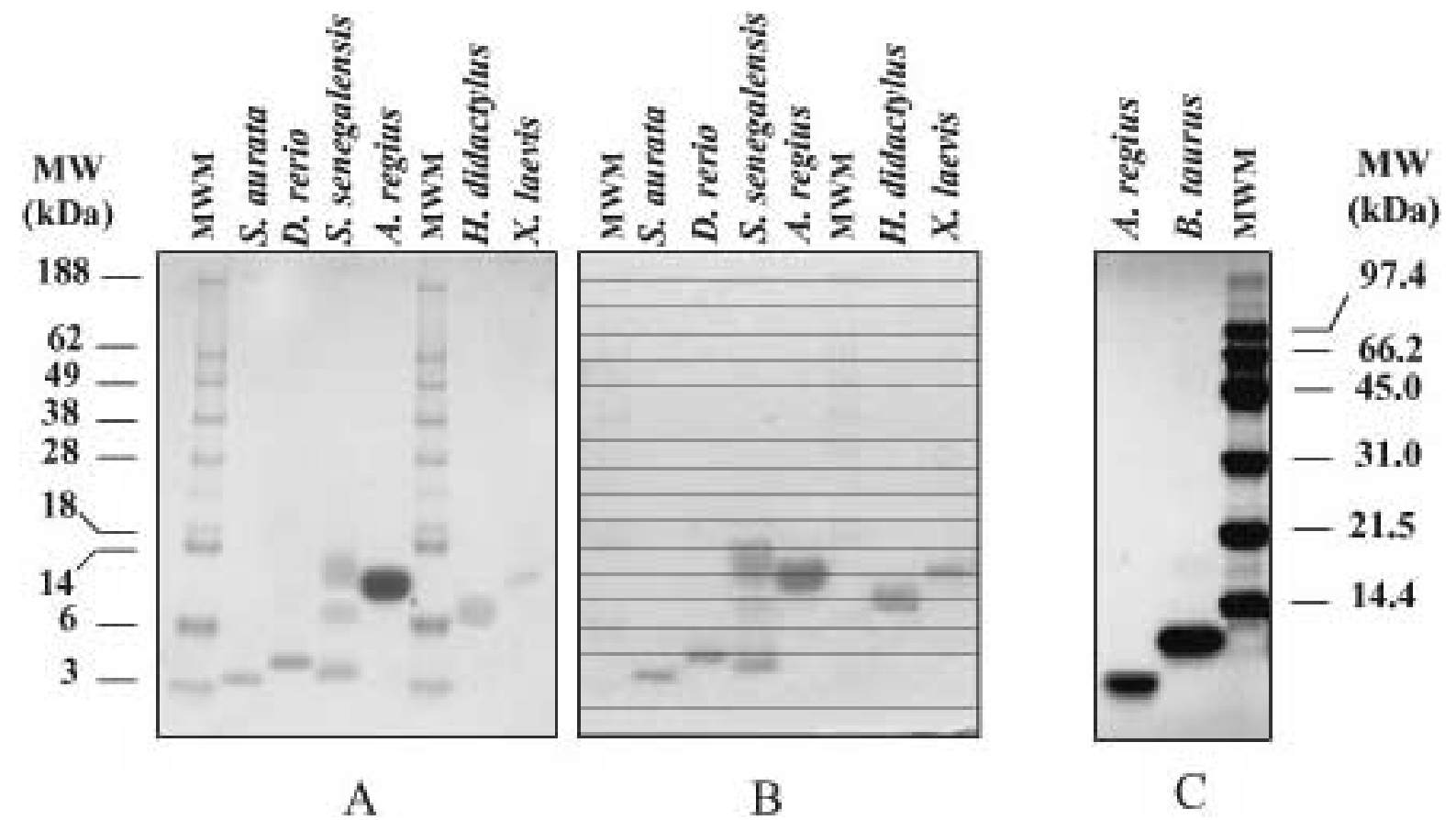

Fig. 1. Comparison of migration behavior on SDS-PAGE of Gla-containing BGPs from different teleosts ( $S$. aurata, $D$. rerio, $S$. senegalensis, $H$. didactylus, $X$. laevis and B. taurus. (A) and (B) Each lane of $12 \%$ SDS-PAGE (Nupage, Invitrogen) was loaded with $10 \mu \mathrm{g}$ of protein. One gel was stained using the CBB-staining method for total protein detection (A) and the other with DBS-staining method specific for Gla-containing

\section{Results}

Identification of Gla-containing Proteins from Mineralized Tissues of Teleost and Cartilaginous Fishes and from Xenopus

BGP and MGP were separated from the acid extract of $S$. aurata, $H$. didactylus, $S$. senegalensis, $D$. rerio and $X$. laevis mineralized tissues by ultrafiltration, as described in Material and Methods. SDS-PAGE results depicted in Figure 1A demonstrate that most of the protein in BGP-containing filtrates from $S$. aurata, D. rerio and $H$. didactylus migrated as a single component with higher mobility than BGP purified from $A$. regius branchial arches, a migration behavior similar to $X$. laevis $\mathrm{BGP}$ (Fig. 1A). Only $S$. senegalensis BGP sample showed more than one band, and the reason for this discrepancy remains to be clarified. In addition, all fish and Xenopus BGPs showed a higher migration behavior than bovine BGP (Fig. 1A, C). Positive reaction (red-orange) obtained with the DBS-staining method (Fig. 1B) following SDS-PAGE clearly indicated that the purified proteins from all species were gamma-carboxylated.

Comparison of the migration behavior between fish (S. aurata, S. senegalensis, A. regius, D. rerio), Xenopus and bovine BGPs in non-denaturing conditions over a 18\% Tris-Glycine native gel is depicted in Figure 2. The results confirm the purity of the fractions analyzed since in this type of gel all protein samples tested migrated proteins (B); MWM, SeeBlue pre-stained molecular weight markers (Invitrogen). (C) Protein $10 \mu \mathrm{g}$ either A. regius or $B$. taurus purified BGP was loaded per lane on a $18 \%$ SDS-PAGE gel (Novex, Invitrogen) and stained with CBB; MWM, low range molecular weight markers from BioRad. Corresponding molecular weights (in $\mathrm{kDa}$ ) are indicated on the margins of the figure.

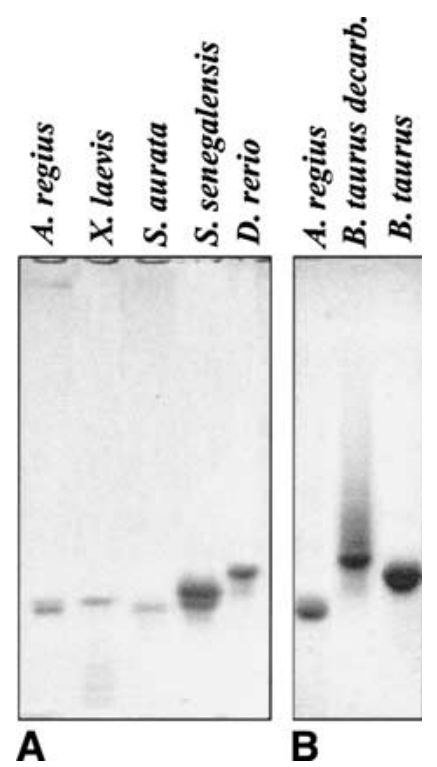

Fig. 2. Comparison of native electrophoresis migration behavior of BGPs from different fish species (A. regius, S. senegalensis, S. aurata and D. rerio), X. laevis and B. taurus applied to $18 \%$ Tris-glycine polyacrylamide gel (Novex, Invitrogen). Each lane was loaded with $10 \mu \mathrm{g}$ of protein and the gel was stained using the CBB staining method. B. taurus decarb - B. taurus BGP decarboxylated (Poser and Price, 1979).

essentially as a major band although a second less intense band is also seen that could be explained by the 
Table 1. Detection and characterization of BGP protein purified from bone and calcified cartilage acid extracts obtained from several teleost fishes (A. regius, S. senegalensis, S. aurata, H. didactylus, D. rerio) and X. laevis

\begin{tabular}{|c|c|c|c|c|c|}
\hline & \multirow[b]{2}{*}{ Specimen (tissue) } & \multicolumn{2}{|c|}{ SDS-PAGE ${ }^{\mathrm{a}}$} & \multirow{2}{*}{$\begin{array}{l}\text { Immunodetection }{ }^{\mathrm{b}} \\
\text { (antibody) }\end{array}$} & \multirow[b]{2}{*}{$\mathrm{N}$-terminal sequence ${ }^{\mathrm{c}}$} \\
\hline & & $\mathrm{CBB}$ & DBS & & \\
\hline \multirow[t]{7}{*}{ BGP } & A. regius (vertebra) & $10 \mathrm{kDa}$ & Positive & Western blot (anti- $A r$ BGP) & AAKELTLAQTE*SLRE*VCE* \\
\hline & & & & & TNMACDEMADAQGIVAAY \\
\hline & S. aurata (vertebra) & $4 \mathrm{kDa}$ & Positive & Western blot (anti- $A r$ BGP) & n.d. \\
\hline & S. senegalensis ${ }^{\dagger}$ (vertebra) & $4 \mathrm{kDa}$ & Positive & Western blot (anti- $A r$ BGP) & n.d. \\
\hline & D. rerio (skeleton) & $5 \mathrm{kDa}$ & Positive & Western blot (anti- $A r$ BGP) & AGTAXGDLTPFQLE*SLRE*VCE* \\
\hline & $\begin{array}{l}\text { H. didactylus } \\
\quad \text { (branchial arches) }\end{array}$ & $8 \mathrm{kDa}$ & Positive & Dot blot (anti-ArBGP) & AAAELSLVQLE*SLRE*VCE*Q \\
\hline & X. laevis (skeleton) & $10 \mathrm{kDa}$ & Positive & —* & n.d. \\
\hline
\end{tabular}

${ }^{a}$ The proteins were electrophoresed on a $18 \%$ SDS-PAGE (NuPage, Invitrogen) stained with $\mathrm{CBB}$ and DBS and the molecular weights were estimated by plotting the log versus relative migration distance using the pre-stained molecular weight markers (SeeBlue, Invitrogen) over a linear range ${ }^{\mathrm{b}}$ Immunodetection of the proteins was performed by Western blot or Dot blot analysis using anti-ArBGP affinity purified antibodies as primary antibody $(0.1 \mu \mathrm{g})$ and alkaline phosphatase-labeled goat anti-rabbit IgG antibody with the NBT/ BCIP substrate solution as secondary antibody

${ }^{\mathrm{N}} \mathrm{N}$-terminal sequence was obtained as described in Materials

presence of a BGP with a different degree of carboxylation. In fact, the effect of carboxylation of BGP is quite clear once we compare, over a native gel, the migration of B. taurus BGP with a sample of decarboxylated protein (Fig. 2B) obtained using a described procedure [23].

N-terminal amino acid sequence analysis was obtained for $\operatorname{DrBGP}$ and $H d \mathrm{BGP}$ (Table 1) and their identity was confirmed based on the fact that the first 21 (DrBGP) and 19 (HdBGP) amino acid residues sequenced showed high homology with previously sequenced BGPs $[15,17]$. The assignment of the three Gla residues in the $\mathrm{N}$-terminal sequence (Table 1) was based on comparison with other BGP sequences [17] where these residues are highly conserved, and also on the fact that in the standard sequence analysis no PTH derivative could be identified at these positions. Western- blot analysis of the fish BGP-containing filtrates from $S$. aurata, D. rerio, $H$. didactylus and $S$. senegalensis using the anti-ArBGP purified antibody (Fig. 3) also confirmed the identification of these bands as BGP.

Analysis by SDS-PAGE of the centricon 30 filterretained contents of each sample followed by CBB and DBS staining permitted the identification of a Glacontaining protein in $X$. laevis, S. aurata and S. senegalensis sample extracts (Fig. 4) with a migration behavior (14-18 $\mathrm{kDa})$ similar to that previously obtained for $\operatorname{ArMGP}$ (Fig. 4). The P. glauca sample showed a clearly defined band (Fig. 4) that was sufficiently pure and abundant to obtain a N-terminal amino acid sequence (30 amino acids residues were obtained, see Table 2) and confirmed its identity to be $P g$ MGP based on its high homology with the previously sequenced and Methods section and is numbered from the first amino acid residue identified from sequence determination, $\mathrm{E}^{*}$, Gla residue. $\mathrm{X}$, non-identified amino acid residue, (n.d.) not determined

+ Besides this one band (3-6 kDa) there were 2 extra bands both coloring with CBB- and DBS-staining (SDS-PAGE, Figure 1) and recognized by the same antibody (Western blot, Figure 3)

* Affinity purified antibodies (anti- $A r$ BGP and anti-ArMGP) as well as anti-GgMGP polyclonal antiserum were tested and gave negative results

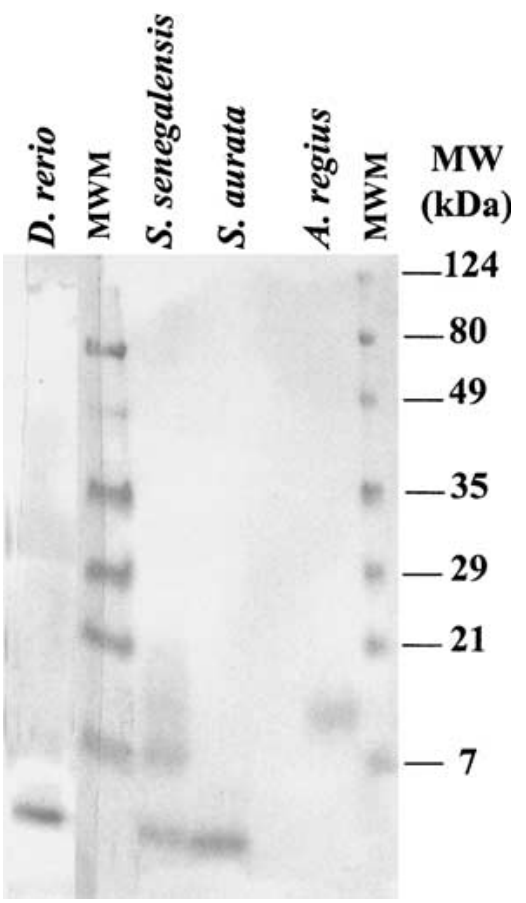

Fig. 3. Western blot analysis of BGPs from several teleost fish. $1 \mu \mathrm{g}$ of each protein was electrophoresed on $18 \%$ SDS-PAGE (Novex, Invitrogen). Following electrophoresis, proteins were blotted onto nitrocellulose, and membranes were incubated with $0.04 \mu \mathrm{g} / \mathrm{ml}$ of anti- $A r$ BGP affinity purified antibody. Alkaline phosphatase-labeled goat anti-rabbit IgG wasused as secondary antibody and NBT/BCIP as substrate solution. MWM, pre-stained molecular weight markers from Bio-Rad. Corresponding molecular weight (in $\mathrm{kDa}$ ) are indicated on the right margin of the figure.

soupfin shark MGP [21]. Western-blot analysis of the filter-retained content in each sample using either the 
Table 2. Detection and characterization of MGP protein in crude or purified bone and calcified cartilage acid extracts obtained from several teleost fish (A. regius, S. senegalensis, S. aurata, D. rerio), X. laevis and blue shark $(P$. glauca)

\begin{tabular}{|c|c|c|c|c|c|}
\hline & \multirow[b]{2}{*}{ Specimen (tissue) } & \multicolumn{2}{|c|}{ SDS-PAGE ${ }^{\mathrm{a}}$} & \multirow{2}{*}{$\begin{array}{l}\text { Immunodetection } \\
\text { (antibody) }\end{array}$} & \multirow[b]{2}{*}{$\mathrm{N}$-terminal sequence ${ }^{\mathrm{c}}$} \\
\hline & & $\mathrm{CBB}$ & DBS & & \\
\hline \multirow[t]{6}{*}{ MGP } & A. regius (branchial arches) & $14-18 \mathrm{kDa}$ & Positive & $\begin{array}{l}\text { Western blot } \\
\quad \text { (anti-ArMGP) }\end{array}$ & $\begin{array}{l}\text { YE*SHESXESAEDLFVPXQ } \\
\text { XANSFMTPXRG }\end{array}$ \\
\hline & D. rerio (skeleton) & $14-18 \mathrm{kDa}$ & Positive & $\begin{array}{l}\text { Western blot } \\
\quad \text { (anti-ArMGP) }\end{array}$ & n.d. \\
\hline & S. senegalensis (vertebra) & 14-18 kDa & Positive & $\begin{array}{l}\text { Western blot } \\
\quad(\text { anti-ArMGP) }\end{array}$ & n.d. \\
\hline & S. aurata (vertebra) & $14-18 \mathrm{kDa}$ & Positive & $\begin{array}{l}\text { Western blot } \\
\quad(\text { anti-ArMGP) }\end{array}$ & n.d. \\
\hline & $X$. laevis (skeleton) & $14-18 \mathrm{kDa}$ & Positive & $\begin{array}{l}\text { Western blot } \\
\quad(\text { anti-GgMGP) }\end{array}$ & n.d. \\
\hline & $\begin{array}{l}\text { P. glauca } \\
\quad \text { (vertebra, jaw, branchial arches) }\end{array}$ & $14-18 \mathrm{kDa}$ & Positive & $\begin{array}{l}\text { Western blot } \\
\quad(\text { anti-GgMGP) }\end{array}$ & $\begin{array}{l}\text { DSSESNEIDDVLFLGRRDA } \\
\text { NSFMKYPQLGN }\end{array}$ \\
\hline
\end{tabular}

${ }^{\mathrm{a}}$ The proteins were electrophoresed on a 4-20\% SDS-PAGE (NuPage, Invitrogen), stained with $\mathrm{CBB}$ and DBS and the relative molecular weight estimated by comparison with prestained molecular weight markers (SeeBlue, Invitrogen)

$\mathrm{b}$ Immunodetection of the protein was performed by Western blot or Dot blot analysis using the anti- $A r$ MGP purified antibodies $(0.1 \mu \mathrm{g})$ or anti- $G g$ MGP polyclonal antiserum (1:100 dilution) as primary antibody and alkaline phosphatase-labe- led goat anti-rabbit IgG antibody with the NBT/BCIP substrate solution as secondary antibody

${ }^{c}$ The N-terminal sequence presented in this table was obtained as described in Materials and Methods section and is numbered from the first amino acid residue obtained from sequence determination. X, non-identified amino acid residue. $E^{*}$, Gla residue, (n.d.) not determined
anti-ArMGP purified antibody or the anti-GgMGP polyclonal antiserum (Table 2) also confirmed the identification of these bands as MGP.

For the $S$. aurata and $S$. senegalensis retentate samples a single band with positive immunoreaction with anti-ArMGP purified antibody was obtained (Fig. 4, A2, B2). These results together with the DBS-staining results performed on the same SDS-PAGE that also gave positive coloration for a band with the same migration behavior (Fig. 4, A1, B1) confirmed that the protein was $\gamma$-carboxylated and that there was no evidence of MGP aggregation. The presence of a second band in the same filter-retained extract (and a third band in the case of $S$. senegalensis sample) with a positive coloration by the DBS-staining but with a higher migration behavior suggested that BGP was present in both $S$. aurata and $S$. senegalensis filter-retained samples (Fig. 4, A1, B1). Western blot using anti- $A r$ BGP purified antibody as a control in these samples, gave positive immunoreaction for BGP confirming the hypothesis of the presence of BGP in $S$. aurata and $S$. senegalensis filter-retained samples (results not shown).

Western-blot analysis of $X$. laevis filter-retained content identified a band around $14-18 \mathrm{kDa}$ with positive immunoreaction with anti-GgMGP polyclonal antiserum that also gave positive coloration with DBSstaining performed on the same SDS-PAGE, confirming that the protein was $\gamma$-carboxylated (Fig. 4, A3, A1). In the case of $D$. rerio, the results obtained by Western blot showed three bands that positively immunoreacted with anti-ArMGP antibody with a pattern of migration behavior similar to $\operatorname{ArMGP}$ (Fig. 4, A2). The absence of any detectable band around $14-18 \mathrm{kDa}$ is possibly due to protein aggregation during the ultrafiltration procedure performed using $5 \mathrm{mM}$ ammonium bicarbonate. This phenomenon is characteristic of MGP especially when stored in non-denaturing buffers as previously referred to $[23,24]$. A comparable result was also observed, although to a less extent, for the $A r$ MGP sample (Fig. 4, A2). However, and in agreement with results obtained for $A$. regius (results not shown), no coloration by DBS-staining was observed for this DrMGP sample (result not shown) probably because of the protein aggregation limiting the exposure of the Gla residues to the staining, an essential feature to obtain a positive result with this staining procedure.

Given the complexity of the protein mixture content in $X$. laevis, S. senegalensis, $S$. aurata and D. rerio filterretained samples, the low efficiency obtained on the separation over a 4-12\% gradient SDS-PAGE (Fig. 4) and also the low MGP content and the aggregation phenomenon, it was not possible to obtain a clear $\mathrm{N}$-terminal amino acid sequence for these samples.

PgMGP sample analysis by Western blot with antiGgMGP polyclonal antiserum showed a positive immunoreaction for the $14 \mathrm{kDa}$ band but a second band was also identified in the precipitant fraction with a higher migration behavior (around 6 kDa) (Fig. 4, C1, $\mathrm{C} 2$ ). This band probably represents fragments of MGP, 


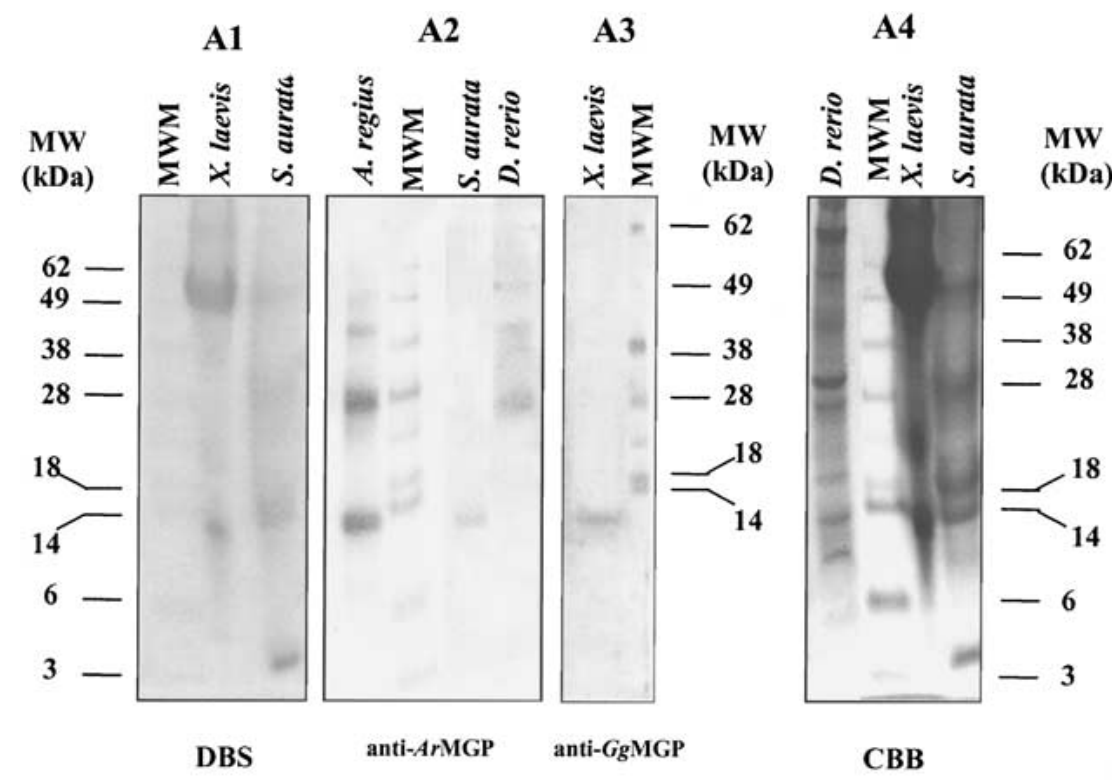

\section{B1 $\quad$ B2 $\quad$ B3}

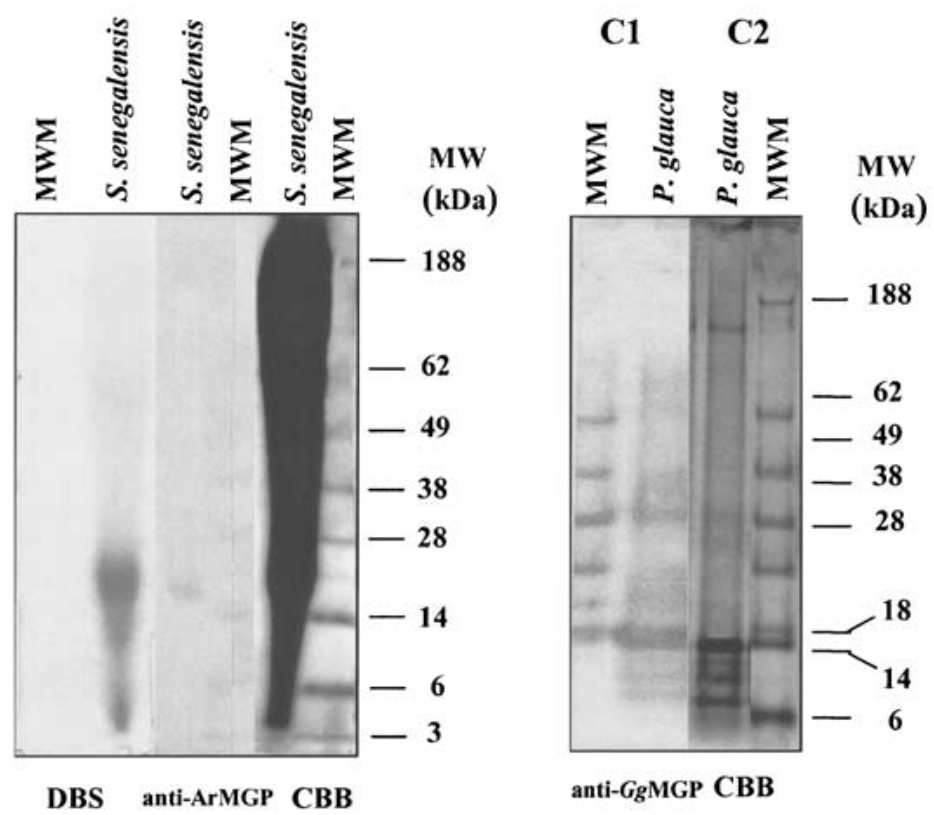

Fig. 4. SDS-PAGE and Western-blot analysis of several teleost fish ( $S$. aurata, $S$. senegalensis, D. rerio, A. regius), X. laevis and $P$. glauca dialyzed acid extracts containing MGP. Electrophoresis was performed using 4-12\% SDS-PAGE gels (Nupage, Invitrogen). Each lane was loaded with $30-50 \mu \mathrm{g}$ of total protein. CBB: Gels were stained using the CBB staining method for total protein detection (A4, B3, C2). DBS: Gels were stained using the DBS staining method specific for Gla residues (A1, B1). anti- $A r$ MGP and anti-GgMGP: for Western blot analysis, a 1:10 dilution of the samples was used to load the gel. Following electrophoresis, proteins were blotted onto nitrocellulose, and the membranes were incubated either with 0.04 $\mu \mathrm{g} / \mathrm{ml}$ of anti- $A r$ MGP purified antibody $(\mathrm{A} 2, \mathrm{~B} 2)$ or 1:100 dilution of anti-GgMGP polyclonal antiserum (A3, C1). Alkaline phosphatase-labeled goat anti-rabbit IgG was used as secondary antibody and NBT/ BCIP as substrate solution as described in the Materials and Methods. MWM, SeeBlue pre-stained molecular weight markers (Invitrogen). a result previously obtained in $A r$ MGP purification from teleost fish-calcified cartilage [15]. Western blot analysis of the insoluble and the soluble dialyzed fraction using the anti- $A r \mathrm{BGP}$ antibodies gave negative results (results not shown).

\section{Antiserum Purification and Characterization}

For use in immunohistochemistry and in the analysis of cell protein extracts, $A r$ BGP and $A r$ MGP polyclonal antisera were affinity-purified, as described in
Materials and Methods, using $A r$ BGP and $A r$ MGP purified from $A$. regius branchial arches [15]. As shown in Figures $5 \mathrm{~A}$ and $5 \mathrm{~B}$, the affinity purification elution profile of both antisera permitted the separation of two different antibody entities, anti- $A r$ BGP-1 and anti$A r$ BGP-2 in $A r$ BGP polyclonal antiserum (5A) and anti- $A r$ MGP-1 and anti- $A r$ MGP-2 in $A r$ MGP polyclonal antiserum (5B). Comparing the relative amount of the elution peaks obtained, anti- $A r \mathrm{BGP}-2(5 \mathrm{~A})$ and anti- $A r$ MGP-1 (5B) purified antibodies seemed to be the most abundant in the unpurified anti- $A r \mathrm{BGP}$ and anti- $A r$ MGP antiserum, respectively. Dot blot analysis 

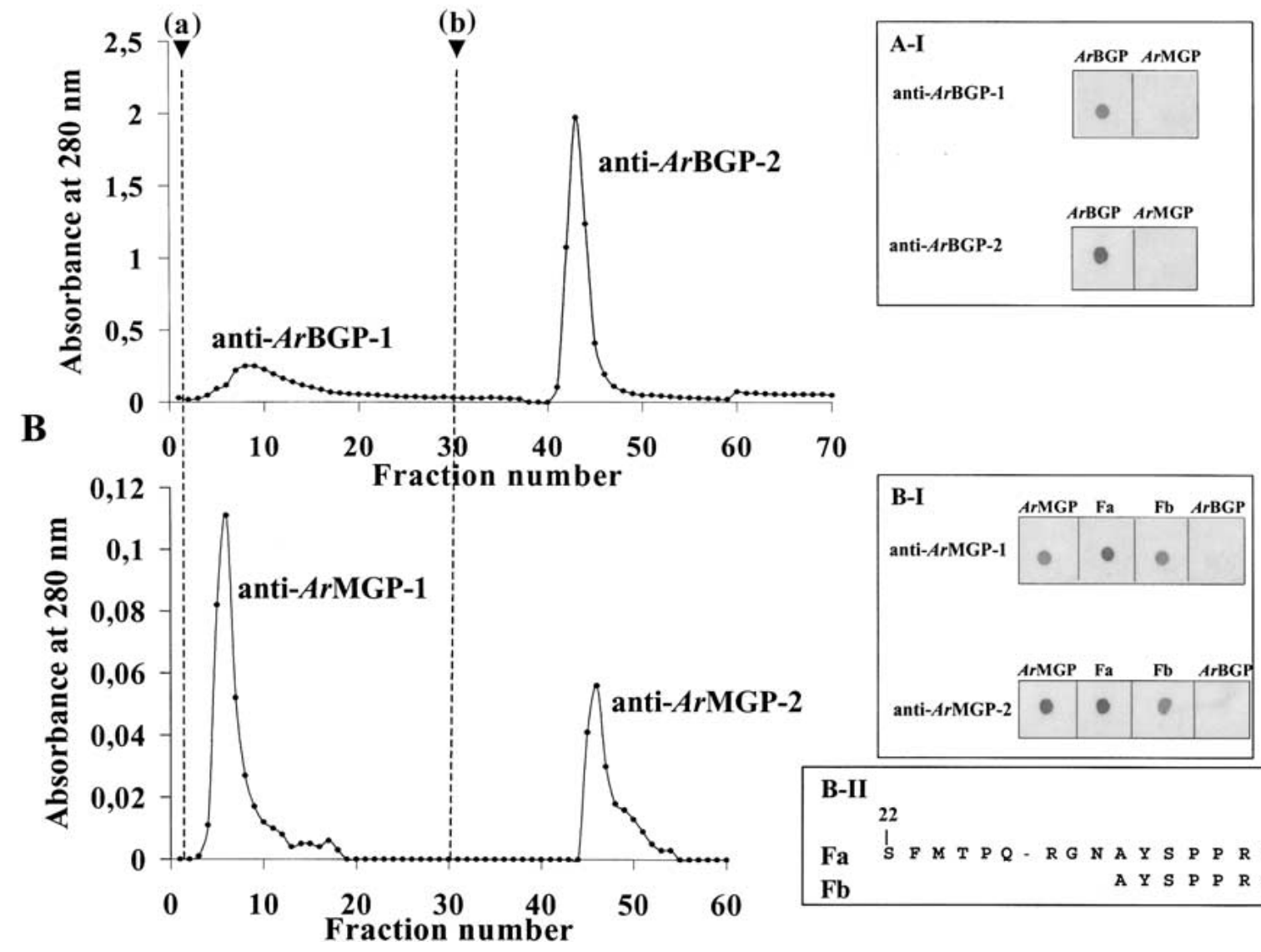

Fig. 5. Affinity purification of anti- $A r B G P(A)$ and anti$A r$ MGP (B) polyclonal antiserum using $\mathrm{CNBr}$-activated Sepharose 4B resin coupled with the corresponding antigen. Bound antibodies were eluted with approximately $100 \mathrm{mM}$ glycine $\mathrm{pH} 2.5$ (a), followed with $100 \mathrm{mM}$ triethylamine, $\mathrm{pH}$ 11.5 (b). Fractions of approximately $1 \mathrm{ml}$ were collected every 5 minutes. Elution profile was obtained by measuring ab-

using different anti-ArBGP purified antibody dilutions against various concentrations of the pure antigen showed that anti-ArBGP-1 and -2 recognized the BGP antigen with the same degree of sensitivity (results not shown).

Characterization of anti-ArMGP-purified antibodies by Dot-blot analysis also showed that anti-ArMGP-1 and -2 recognized both $A r \mathrm{MGP}$ antigen and the purified $A r$ MGP fragments [15] with the same degree of sensitivity, as tested by Dot blot analysis (Fig. 5B-I, BII). Relative specificity of these antibodies was further tested using different antibody dilutions against various concentrations of purified MGP and polypeptide fragments and shown to be both equally specific for the fragments and the mature protein (results not shown).

Our results also indicate that the anti-ArMGP and anti- $A r$ BGP purified antibodies were 100 times more

sorbance of effluent fractions at $280 \mathrm{~nm}$. Peak fractions were collected and dialyzed with phosphate buffer saline (PBS). Immunoreaction of $0.1 \mu \mathrm{g}$ of $A r \mathrm{MGP}, A r \mathrm{BGP}$ or polypeptide $A r \mathrm{MGP}$ fragments ( $\mathrm{Fa}$ and $\mathrm{Fb}, \mathrm{B}-\mathrm{II})$ upon treatment with 0.04 $\mu \mathrm{g} / \mathrm{ml}$ of anti- $A r$ BGP purified antibodies (A-I) and anti$A r$ MGP purified antibodies (B-I) obtained by Dot-blot analysis, as described in Materials and Methods.

sensitive than the unpurified antiserum since a dilution of 1:10,000 (corresponding to the same total protein concentration of originally unpurified antiserum) could detect $10 \mathrm{ng}$ of purified antigen (results not shown).

Immunodetection of BGP and MGP Proteins from Different Teleost Fish, X. laevis and P. glauca Using ArBGP, ArMGP and GgMGP Antibodies

Specificity of both the affinity-purified anti- $A r$ BGP and anti-ArMGP and the non-purified anti-GgMGP antibodies was confirmed by Western blot analysis. The specificity was further tested by comparing its reaction with BGP and MGP proteins extracted from several teleost, a cartilaginous fish and Xenopus.

Recognition of $S$. aurata, $S$. senegalensis and D. rerio BGPs by anti- $A r$ BGP purified antibodies was assessed 
Table 3. Immunodetection results for MGP and BGP extracted from several teleost fishes (A. regius, $S$. aurata, $S$. senegalensis, D. rerio), $X$. laevis and $P$. glauca using the affinity purified anti- $A r$ MGP $(0.1 \mu \mathrm{g})$ and anti- $A r$ BGP antibodies $(0.5$ $\mu \mathrm{g}$ ) and the anti-GgMGP polyclonal antiserum (1:100 dilution). Relative specificity was deduced from Western blot and Dot blot analysis (as described in Materials and Methods) using the same concentration of antigen and primary antibody

\begin{tabular}{llll}
\hline Antibody & Antigen & Species & Relative specificity \\
\hline \multirow{4}{*}{ anti-ArBGP } & BGP & A. regius & +++ \\
& & S. aurata & ++ \\
& & S. senegalensis & ++ \\
& & H. didactylus & ++ \\
& & D. rerio & ++ \\
anti-ArMGP & MGP & X. laevis & - \\
& & A. regius & +++ \\
& & S. aurata & ++ \\
& & S. senegalensis & ++ \\
& & P. glauca & + \\
anti-GgMGP & MGP & D. rerio & ++ \\
& & X. laevis & - \\
& & X. lauca & +++ \\
& & A. regius & ++ \\
& & & ++ \\
\hline
\end{tabular}

by Western blot (Fig. 3) using the proteins purified from acid extracts of calcified tissues (Table 1). A positive reaction with anti- $A r$ BGP antibodies was seen by Dot blot assay with $H$. didactylus BGP while no positive reaction was observed for XlBGP (Table 1).

Positive immunoreaction of $S$. aurata, S. senegalensis and $D$. rerio MGPs was seen by Western blot analysis using the anti- $A r$ MGP purified antibodies as depicted in Figure 4. However, this antibody did not recognize $X$. laevis MGP whereas P. glauca MGP was recognized but with a lower specificity than teleost fish MGPs (Table 3). However, both $P$. glauca and X. laevis MGPs were immunodetected by Western blot using anti-GgMGP polyclonal antiserum (Table 3 ).

\section{Discussion}

Based on previous results obtained in higher vertebrates (B. taurus) [25], in X. laevis and the teleost fishes Xiphias gladius, $S$. aurata and $A$. regius $[15,17,26]$, we were able to purify and characterize BGP from the vertebra and jaw of several other marine teleost fishes ( $S$. senegalensis and $H$. didactylus), and from the entire mineralized skeleton of a fresh water teleost (D. rerio). In contrast with mammals, two major histological types of bone can be found in teleost fish (cellular and acellular bone) [27, 29]. Despite these structural differences, our results indicate that in fish, as in mammals [26], fish bone-like mineralized tissue is the major site of accumulation for BGP $[14,15,17]$ supporting the hypothesis that BGP function is likely to be associated with bone in all vertebrates. Comparison of $A$. regius BGP SDS-PAGE migration profile with those from other teleosts $(S$. senegalensis, $S$. aurata, $H$. didactylus and $D$. rerio), as well as from $X$. laevis and $B$. taurus, showed clear differences. While $X$. laevis, $H$. didactylus and $A$. regius BGPs had a similar behavior and migrated more like the B. taurus protein, the $S$. aurata and D. rerio BGPs migrated as smaller entities (Fig. 1). This result cannot be explained solely by the known molecular weight difference between the proteins, or by the differences in gamma-carboxylation, since the results of $\mathrm{N}$-terminal sequence obtained (A. regius [15], $H$. didactylus and $D$. rerio, (this study), $S$. aurata and $X$. laevis [17], and $B$. taurus [29]) showed that BGP was always fully gammacarboxylated at each of the three Gla residues. Comparison between calculated isoelectric points (pI) (Table 4) also does not reflect the anomalous migration behavior in SDS-PAGE since they all have low pIs. In contrast, the relative migration behavior of these BGPs on native polyacrylamide gels (Fig. 2) correlates better with the differences observed between their calculated pIs (Table 4), suggesting the presence of different levels of gamma-carboxylation.

Comparing the gel filtration purification profiles for BGP from different fishes (swordfish [26], S. aurata [17], L. macrochirus [16] and A. regius [15]) and considering the different levels of purity achieved in each reported experiment using similar techniques, we conclude that the BGP content in bone-like mineralized tissues seems to be dependent not only on the origin of the tissue but also on the fish species and stage of development. Different contents of BGP in vertebra may reflect not only the cellular versus acellular nature of the bone (depending on the species analyzed) but also on the requirement for this protein, which may vary depending on growth stage in teleosts.

This study reports for the first time the identification of MGP in acid extracts of teleosts vertebra. The identification of MGP in the teleosts S. senegalensis, $S$. aurata and $D$. rerio suggests that the level of MGP accumulation in teleost fishes mineralized tissues is also probably dependent on the stage of development since previous experiments failed to purify MGP from teleost fish vertebra acid extracts [15, 17]. This evidence is further supported by our previous immunohistochemistry results where we found that MGP can accumulate in $A$. regius neural arch vertebra in regions counterstaining with Alcian Blue (stains positive for mucopolyssacarides) [15]. The full characterization of this extracellular matrix by in situ hybridization and immunohistochemistry will be the subject of future studies once additional specific molecular markers are available for this fish, a work presently ongoing in our laboratory. Differences between the levels of MGP accumulation in vertebra of young and adult fishes may also 
Table 4. Comparison of descriptive information based on BGP amino acid sequences of B. taurus, X. laevis, A. regius, S. aurata and D. rerio obtained using Peptide Statistics Tool (PEPSTATS) from biotools (http://biotools.umassmed.edu) ${ }^{\mathrm{a}}$

\begin{tabular}{llccccc}
\hline & B. taurus & X. laevis & A. regius & S. aurata & D. rerio* \\
\hline & Molecular weight (Da) & 5704.33 & 5359.79 & 4868.49 & 4950.63 & 5209.89 \\
& Isoelectric point (pI) & 4.21 & 4.08 & 3.76 & 3.87 & 4.10 \\
& Number of residues & 49 & 49 & 45 & 45 & 48 \\
Types of residues & 8 & 8 & 7 & 10 & 8 \\
& Aliphatic & 9 & 6 & 4 & 5 & 6 \\
& Aromatic & 31 & 28 & 28 & 29 & 30 \\
& Non-polar & 18 & 21 & 17 & 16 & 18 \\
& Polar & 16 & 12 & 9 & 8 & 9 \\
& Charged & 6 & 4 & 2 & 6 & 3 \\
& Basic & 10 & 8 & 7 & 6 & 6 \\
\hline
\end{tabular}

Sequence GenBank accession numbers are: AF459030 for Argyrosomus regius; AF048703 for Sparus aurata (seabream); AF055576 for Xenopus laevis; X53699 for bovine (Bos taurus); AY078413.1 for Danio rerio

* The complete mature sequence derived from nucleotic analysis was used for this comparison obtained from AY078413.1 (Gavaia, Simes et al., 2003 submitted)

${ }^{a}$ Values were calculated for BGP in the absence of hydroxyproline and $\gamma$-carboxylation of glutamic acid residues reflect changes in the degree of mineralization found throughout development and in adult life and could be related to variable MGP synthesis rates at different periods of life or different requirement for MGP as the fish grows. These results are in contrast with data obtained in mammals in which it was shown that MGP accumulates at similar levels in bone of fetus or adult rats [11]. The presence in teleost fish MGPs of an extended C-terminus enriched in basic amino acids also found in shark $[15,21]$ and never found in mammalian MGPs, could be one of the reasons for the apparent higher affinity of the MGP for the mucopolisacariderich extracellular matrix found in branchial arches calcified cartilage and vertebra of fish.

Following the purification of MGP and BGP from $A$. regius mineralized tissues, the generation of specific polyclonal antibodies was successfully accomplished, as seen when tested for specificity and sensitivity for each specific antigen by Western blot analysis. The results obtained clearly showed that the anti-ArMGP polyclonal antiserum only recognized fish MGP and not fish BGP and that anti-ArBGP polyclonal antiserum was also specific for BGP [15].

To increase antibody specificity for use in immunohistochemistry studies, both polyclonal antisera were affinity-purified. Analysis of their purification profile suggested the presence of different antigen recognition sites in these antibodies, resulting in the purification of two separate peaks, each one in different elution conditions (acid and basic) (Fig. 5A, B). Both antibodycontaining fractions resulted in comparable results when tested for immunoreactivity at different dilutions against the purified mature proteins. In the case of antiArMGP antibodies, immunoreactivity against the purified MGP polypeptide fragments was also tested and both purified anti- $A r$ MGP antibody entities gave comparable results (Fig. 5B-I, B-II). Based on these results and since the two ArMGP fragments comprised most of the mature protein (fragment $\mathrm{Fa}$ extended from residue 22 to the $\mathrm{C}$-terminal residue, fragment $\mathrm{Fb}$ from residue 31 to the C-terminal residue) the possibility that the two antibodies recognize different epitopes cannot be inferred.

Immunodetection results obtained by Western blot using the affinity purified anti-ArMGP and antiArBGP antibodies showed that anti-ArMGP specifically identified MGPs extracted from $S$. senegalensis, $S$. aurata, $D$. rerio and to a lower extent from $P$. glauca but did not immunoreact with $X$. laevis MGP (Table 3 ), a result that can be explained by the higher degree of sequence homology of the $X$. laevis sequence with MGPs from mammals and birds than with A. regius MGP [15]. Interestingly, the $X$. laevis MGP was found to immunoreact with another MGP polyclonal antiserum previously developed against shark MGP (anti$G g \mathrm{MGP}$ ), a result that is not surprising given the features that shark and $X$. laevis MGPs have in common, namely the presence of an aspartic acid at position 2 and not a Gla residue which is seen in all other MGP sequences including $A$. regius [15]. However, this reaction was not as strong as was seen with MGP purified from a different shark (Prionace glauca) as expected.

Immunoreactivity of BGPs isolated from $S$. senegalensis, S. aurata, D. rerio and $H$. didactylus was also tested by Western blot and the results clearly showed that the purified anti- $A r$ BGP polyclonal antibodies were able to specifically recognize BGP purified from each of these different teleosts. As seen for MGP, the purified ArBGP polyclonal antibody did not recognize BGP extracted from Xenopus bone (XlBGP) (Table 3). This result has some consistency after comparison with the presently known fish BGP sequences $[15,30]$ since amphibian BGP is more closely related to bird and mammalian BGPs than to the fish proteins. The most notable 
features are the conserved $\mathrm{N}$-terminal insertion in bird, mammalian and Xenopus that is absent in teleosts and a homologous C-terminal in all Xenopus, bird and mammalian BGPs that is not conserved in fish BGPs.

The validation of these important biochemical tools in the recognition of either BGP or MGP antigen from different teleosts species, as well as from $X$. laevis and $P$. glauca, which are currently being studied in our laboratory, should be useful to further understand the deposition, distribution and developmental appearance of these proteins in non-mammalian vertebrates, thus providing further insight into its function throughout vertebrate evolution. The purified antibodies can now allow the establishment of specific immunoassays to adequately measure circulating levels of fish BGP and MGP, as already seen in the mammalian system. Another potential use of these tools may be to simplify purification procedures since they can be used to affinity purify these Gla-containing proteins from bone and calcified cartilage demineralized extracts.

Acknowledgments. This work was partially funded by grants from the Portuguese Science and Technology Foundation (Praxis BIA 469/94; BIA 11159/98; POCTI/CVT/42098/2001) and US Public Health Service, Grant AR25921 from the National Institutes of Health. DC Simes was the recipient of a PRODEP fellowship awarded by the Portuguese Ministry of Education. N-terminal amino acid sequences for $\operatorname{DrBGP}$, $H d \mathrm{BGP}$ and $P g$ MGP were submitted to SWISS-PROT database and were assigned accession numbers P83238, P83473 and P83347, respectively.

\section{References}

1. Hauschka PV, Lian JB, Cole DEC, Gundberg CM (1989) Osteocalcin and matrix Gla protein: vitamin K-dependent proteins in bone. Physiol Rev 69:990-1047

2. Ducy P, Desbois C, Boyce B, et al. (1996) Increased bone formation in osteocalcin-deficient mice. Nature 382:448452

3. Luo G, Ducy P, McKee MD, Pinero GJ, Loyer E, Behringer RR, Karsenty G (1997) Spontaneous calcification of arteries and cartilage in mice lacking matrix gla protein. Nature 386:78-81

4. Yagami K, Suh J-Y, Enomoto-Iwamoto M, Koyama E, Abrams WR, Shapiro IM, Pacifici M, Iwamoto M (1999) Matrix gla protein is a developmental regulator of chondrocyte mineralization and, when constitutively expressed, blocks endochondral and intramembranous ossification in the limb. J Cell Biol 147:1097-1108

5. Shanahan CM, Proudfoot D, Farzaneh-Far A, Weissberg PL (1998) The role of Gla proteins in vascular calcification. Crit Rev Eukaryotic Gene Express 8:357-375

6. Price PA, Faus SA, Williamson MK (1998) Warfarin causes rapid calcification of the elastic lamellae in rat arteries and heart valves. Arterioscler Thromb Vasc Biol 18:1400-1407

7. Shanahan CM, Cary NRB, Salisbury JR, Proudfoot D, Weissberg PL, Edmonds M (1999) Medial localization of mineralization-regulating proteins in association with monckeberg's sclerosis, evidence for smooth cell-mediated vascular calcification. Circulation 100:2168-2176

8. Price PA, Faus SA, Williamson MK (2000) Warfarininduced artery calcification is accelerated by growth and vitamin D. Arterioscler Thromb Vasc Biol 20:317-327
9. Shanahan CM, Proudfoot D, Tyson KL, Cary NRB, Edmonds M, Weissberg PL (2000) Expression of mineralization-regulating proteins in association with human vascular calcification. Z Kardiol 89:63-68

10. Spronk HMH, Soute BAM, Schurgers LJ, Cleutjens JPM, Thijssen HHW, De Mey JGR, Vermeer C (2001) Matrix gla protein accumulates at the border of regions of calcification and normal tissue in the media of the arterial vessel wall. Biochem Biophys Res Commun 289:485490

11. Otawara Y, Price PA (1986) Developmental appearance of Matrix gla protein during calcification in rat. J Biol Chem 261:10828-10832

12. Hale JE, Mattew KW, Price PA (1991) Carboxyl-terminal proteolytic processing of matrix gla protein. J Biol Chem 266:21145-21149

13. Price PA, Rice JS, Williamson MK (1994) Conserved phosphorylation of serine in the Ser-X-Glu/Ser(P) sequences of the vitamin K-dependent matrix gla protein from shark, lamb, rat, cow and human. Protein Sci 3:822830

14. Cancela ML, Williamson MK, Ohresser MCP, Reia JP, Price PA (2001) Matrix gla protein in Xenopus laevis: molecular cloning, tissue distribution and evolutionary considerations. J Bone Miner Res 16:1611-1621

15. Simes DC, Williamson MK, Ortiz-Delgado JB, Viegas CSB, Cancela ML, Price PA (2003) Purification of Matrix Gla Protein (MGP) from a marine teleost fish, Argyrosomus regius: calcified cartilage and not bone as the primary site of MGP accumulation in fish. J Bone Miner Res $18: 244-259$

16. Nishimoto SK, Araki N, Robinson FD, Waite JH (1992) Discovery of bone $\gamma$-carboxyglutamic acid protein in mineralized scales. The abundance and structure of Lepomis macrochirus bone $\gamma$-carboxyglutamic acid. J Biol Chem 267:11600-11605

17. Cancela ML, Williamson MK, Price PA (1995) Aminoacid sequence of Bone Gla Protein from the African clawed toad Xenopus laevis and the fish Sparus aurata. Int J Peptide Protein Res 46:419-423

18. Delmas PD, Christiansen C, Mann KG, Price PA (1990) Bone Gla Protein (osteocalcin) assay standardization report. J Bone Miner Res 5:5-11

19. Jie K-SG, Gijsbers BLMG, Vermeer C (1995) A specific colorimetric staining method for $\gamma$-carboxyglutamic acidcontaining proteins in polyacrylamide gels. Anal Biochem 224:163-165

20. Sambrook J, Fritsch EF, Maniatis T (1989) Molecular cloning: a laboratory manual. Cold Spring Harbor Laboratory Press, New York

21. Rice JS, Williamson MK, Price PA (1994) Isolation and sequence of the vitamin K-dependent Matrix Gla Protein from the calcified cartilage of the soupfin shark. J Bone Miner Res 9:567-576

22. Poser JW, Price PA (1979) A method for decarboxylation of the $\gamma$-carboxyglutamic acid in proteins. J Biol Chem 254:431-436

23. Fraser JD, Price PA (1990) Induction of Matrix Gla Protein synthesis during prolonged 1,25-Dihydroxyvitamin $D_{3}$ treatment of osteosarcoma cells. Calcif Tissue Int 46:270-279

24. Fraser JD, Otawara Y, Price PA (1988) 1,25-Dihydroxyvitamin $\mathrm{D}_{3}$ stimulates the synthesis of matrix $\gamma$-carboxyglutamic acid protein by osteosarcoma cells. J Biol Chem 263:911-916

25. Price PA, Otsuka AS, Poser JW, Kristaponis J, Raman N (1976) Characterization of a $\gamma$-carboxyglutamic acid-containing protein from bone. Proc Natl Acad Sci USA 73:1447-1451

26. Price PA, Otsuka AS, Poser JW (1977) Comparison of gamma-carboxyglutamic acid-containing proteins from bovine and swordfish bone: primary stucture and $\mathrm{Ca}^{2+}$ binding. In: Wasserman RH, Corradino RA, Carafoli E, Kretsinger RH, Mac-Lennan DH, Siegel FL (Eds.) Cal- 
cium-binding proteins and calcium function. Elsevier North-Holland, Amsterdam, pp 333-337

27. Witten PE (1997) Enzyme histochemical characteristics of osteoblasts and mononucleated osteoclasts in a teleost fish with acellular bone (Oreochromis niloticus, Cichlidae). Cell Tissue Res 287:591-599

28. Witten PE, Hansen A, Hall BK (2001) Features of monoand multinucleated bone-resorbing cells of the Zebrafish
Danio rerio and their contribution to skeletal development, remodeling and growth. J Morph 250:197-207

29. Price PA, Poser JW, Raman N (1976) Primary structure of the gamma-carboxyglutamic acid-containing protein from bone. Proc Natl Acad Sci USA 73:3374-3375

30. Viegas CS, Pimto JP, Conceicao N., Simes DC, Cancela ML (2002) Cloning and characterization of the cDNA and gene encoding Xenopus laevis osteocalcin Gene 289: 97-107 